\title{
"It Is Not Our Business": Perceptions of Department Heads of Teacher Education Programs Regarding Inclusion
}

\author{
Orit Gilor, Pnina Shavit \\ Beit Berl College, Israel
}

\begin{abstract}
Implementing changes in the education system requires the mobilization of all parties. Teacher education, as part of the education system, should help in implementing the changes. This study focuses on the change resulting from a policy of inclusion pupils with special needs in the regular education system. The goal of this study was to identify attitudes of department heads of teachers training towards inclusion and their responsibility for the implementation of inclusion policy into teacher education programs. The results show that not all heads departments do not feel professional responsibility for implementing inclusion. They interpret policy according to their role position perception, and according to their limited knowledge about inclusion. Recommendations for change in teacher education in light of these findings can serve as a model to other places around the world.
\end{abstract}

Keywords: teacher education, training teachers, inclusion, education policy-makers, department heads, pupils with special needs

\section{Introduction}

\section{Educational Policy}

Educational policy mandates the inclusion of pupils with special needs within the general educational framework alongside their peers. In Israel, this policy is based on the Special Education Law (1988) and the regulations that followed, which give priority to the placement of pupils with disabilities in general education settings. The basis of this policy is the natural right of every human being to equal opportunities, and society's responsibility to create the conditions necessary to achieve the full realisation of the individual's potential.

Over the past three decades, during which inclusion policy has been implemented worldwide, educators and stakeholders have constantly discussed and debated the challenges that educators face in implementing inclusion. The inclusion policy demanded very big change in the educational system (Sebba \& Ainscow, 1996). The difficulty of translating the ideal of inclusion and every pupil's right to be educated alongside his peers without disabilities into reality is an issue that engages educators.

The successful implementation of inclusion depends on numerous factors, such as the allocation of resources needed to implement inclusion (Balas \& Adler, 2004); how the school principals perceive and implement inclusion (Avissar, Reiter, \& Leyser, 2003; Day et al., 2009; Graham \& Spandagou, 2011; Muijs et al., 2010); the school's organizational climate (Dorczak, 2011); and the school's relationship with the 
community (Ainscow, Dyson, Goldrick, \& West, 2012). In addition, research has shown that the quality of teachers makes the most significant contribution to pupils' achievements, to a greater extent than any other factor such as class size, class composition, and the pupils' background (Donnelly, 2010). Effective teacher education is the essential step to become a good teacher. In other words, teacher education should prepare teachers to teach effectively inclusive classes.

\section{Teacher Education}

New guidelines for teacher education frameworks were authorized by the Israeli Council for Higher Education following the Ariav Committee's report (2006), and were updated in 2008. The new framework specified the core themes of the teacher education departments, and granted the various institutions flexibility for determining the courses' contents and scope. Among the essential content in the "basic framework" is the teaching-learning process for pupils with special needs and those coming from different sociocultural backgrounds. It is a core theme that must be reflected in the teacher education departments, including both theoretical aspects and guided practicum experience. Thus, the need to incorporate the topic of inclusion in teacher education required that teacher education programs be restructured.

All teacher education colleges in Israel offer unique training departments for the different educational settings. Each department has its distinctive curriculum, aimed at training pre-service teachers to become successful and effective teachers in the educational framework they enter. The departments train pre-service teachers for either the general or the special education frameworks, and for different age-levels - early childhood, primary school, and high school. Each department is headed by a person who fills an academic management role, and is responsible for taking economic, technological, political and societal changes into account (Kezar \& Eckel, 2002). Department heads (DH) must be qualified to lead the organizational processes necessitated by these changes (Kedem, Fakhereldeen, \& Ben-Israel, 2012). In other words, the heads of the departments must set the policy of their departments and see to it that the policy is reflected in the various courses.

These adaptations require professionalism. Even though the implementation of social changes requires knowledge about socio-political topics, many people holding academic management positions do not feel it necessary to acquire. They prefer to acquire managerial tools and know-how, as well as the ability to take a broad view of the entire organization (Marshall, Adams, Cameron, \& Sullivan, 2000). In the context of training teachers for inclusion, there is also importance for political and social changes to be considered. Political changes are reflected in awareness of the Ministry of Education's policy, laws such as the Special Education Law (1988), and the regulations governing the Pupils' Inclusion Department (Director-General's Bulletin, 2008/3 (D) 1 November 2007). In this context, social changes refer to the implementation of the policy regarding the inclusion of pupils with special needs.

\section{Attitudes}

This study focus on the implementation of inclusion policy by people in leadership positions in the teacher education system. According to the theory of planned behaviour (Fishbein \& Ajzen, 2010), people's attitudes, as well as their efficacy and perceptions of social norms, strongly influence their actual behaviour. Hence, it's important to examine the attitudes of the heads of teacher education departments.

The various definitions of the term "attitudes" view attitudes as a tendency to react in a specific way. We can say that an attitude expresses the extent to which an individual is for or against something. 
The research literature defines positive attitudes towards people with special needs as "a belief that sees an individual with disabilities as an active member of society, who makes decisions concerning his personal interests and leads a normal life" (Tervo, Palmer, \& Redinius, 2004, p. 908).

This research seeks to examine whether, and if so how, the attitudes of DH contribute to the implementation of inclusion policy. The goal of this study was to examine the DH perception of their role in implementing inclusion policy. To this end, we asked questions about how they perceive the policy and its implementation in schools and in teacher education.

\section{The Research Questions}

What is the attitude of the DH of teacher education toward the inclusion policy and it's implementation? What role does teacher education play in implementing the inclusion policy, from DH perspective?

\section{Method}

\section{Participants}

Participants in the research included 18 DH (three male and 15 female) who attended, three forums of the Institute for Teacher Education (MOFET): a forum for heads of special education departments (8 participants), a forum for heads of primary education departments ( 5 participants), and a forum for heads of early-childhood education departments (5 participants). The participants represented the various sectors of Israeli society (Jewish, religious Jewish and Arab). All 18 have terminal degrees in education. They are academics who have taken on the roles of college department heads, and they perform this role for a period of between one and five years.

\section{Instrument}

Protocols of group discussions that were held in all three forums of heads of departments.

The discussions tried to clarify the perceptions and attitudes of the group's members regarding the following topics: What constitutes inclusion? Which conditions are needed for successful inclusion? What should pre-service teachers be taught about inclusion, and at what point in their career?

\section{Procedure}

In an exploratory phase prior to this study, personal interviews were conducted with a number of DH on issues relating to inclusion. Statements made by the interviewees were extracted from the findings of that stage, and served as the basis for the discussions in the forums. Between two and five statements representing the range of attitudes and perceptions on each of the topics were prepared by the researchers.

Meetings were held with all three forums. Forum meetings are usually devoted to a discussion on issues of concern to the department heads. At the three meeting devoted to this study, three researchers attended every meeting, each of which lasted between an hour and a half, and two hours. At the start of the meeting, one researcher presented the research topic and its goals, and afterwards each participant received a hand-out with the statements. Participants were asked to choose the statement which best reflected their position on that topic and also to note the grounds for their choice. Afterwards a group discussion took place, facilitated by one of the researchers, during which the participants could express their reactions to each of the five aforementioned topics. The discussions were recorded, with the participants' knowledge and consent, and the two other researchers who were present at the meetings took notes. After the meetings, the two researchers compared their notes with the recording. 


\section{Data Analysis}

The research utilized a qualitative methodology. An analysis of the group discussions was performed, integrating content analysis of the participants' statements (what they said about the presented statement) and discourse analysis, which addressed the linguistic aspects and adhered closely to the manner in which they presented their statements (Titscher, Meyer, Wodak, \& Vetter, 2000).

Content analysis, which is also considered as discourse analysis (Titscher et al., 2000), included a rereading of the text in full, a division of the text into noteworthy recurring themes, and a division into sub-themes. At the end of the process, a comparison was made between the attitudes of participants in the different groups.

\section{Findings}

This research focus on the changes required to implement the policy of inclusion for pupils with special needs in general educational settings. The research examined the perception of DH in academic management positions in the teacher education colleges regarding this policy, and how they perceived their role in its implementation. The findings indicated that there is consensus regarding the policy of the inclusion. At the same time, with that being said, differences among the heads of the various departments were found regarding their roles and responsibilities for implementing inclusion.

The findings will be presented according to the research questions.

\section{Attitudes Towards the Inclusion Policy and Its Implementation}

All the research participants viewed the inclusion of pupils with special needs in general education settings as a basic human right, a right stems, they maintained, from a humanistic philosophical approach: "An elementary human principle unconnected to difficulty, being part of society"; "It's every individual's right... as a humanist value. An inherently human right... and of course it enhances the value of differences among people"; "A person's right to live within society like everyone"; “... and it's the system's mission to enable their inclusion”.

Despite the stated unanimity concerning an individual's right to be included within society, when we discussed the implementation of inclusive principles as part of training teachers, the DH raised many dilemmas. The discussion focused on the inclusion of students with special education needs (SEN) in the colleges in general, and in teacher education programs. Engaging with this issue led the participants to make statements that contradicted the positive attitudes towards inclusion that they had expressed at the start of the discussion, and the humanistic outlook to which their attitudes were anchored. The participants cited reservations about inclusion on the college campus. Most of the reservation raised regarding the degree of students' ability to comply with professional standards - as one early childhood department head said: "In the practicum, no one gives you accommodations-like they do in the lecture-hall. Children must get the best nursery-school teacher possible". People with special needs are encouraged to enter professions such as teaching; however, this is, conditional on their meeting the standards that all students must comply with, particularly in the practical part of training. This a-priori restrictive condition illustrates the gap between the humanistic social outlook and its de-facto implementation in training future teachers. The restrictive condition that exists for every student, with and without SEN, but is specifically stated during the admission process just for students with SEN.

For the DH, the attempt to implement inclusion as part of their worldview-is not an easy one: "I also experience this (the difficulty). We had (a candidate for studies) with Asperger's syndrome, and I sat on the 
admissions committee and fought for his admission so he could fulfill his life-long dream". Some maintained that responsibility for admitting students with special needs is not theirs, but rests with the presidents of the colleges; that is, people in positions higher than their own. "Did you do this (attitude research) with the heads of the college? Because I had to fight for a woman with special needs to be admitted to the college". This raises the question of how each one sees his role as head of a department — whether he views himself as having the authority to admit students with special needs into his department.

In discussing the question of the implementation of policies in the education system is apparent that the descriptions that the DH gave about the difficulties of implementing inclusion reflect the way they perceive their role as educators. The heads of training departments who viewed their role as generating change in society and themselves as activists for achieving that goal: "It depends on us. It depends on how you organize (the infrastructure)". Those who did not see their role as agents of change spoke about the disadvantages of inclusion or who emphasized the conditions that impede inclusion: "No one, in the educational system, says what they will provide. If they provide the conditions, the crutches (support), for inclusion - I agree. It's not clear to me what is being provided in order for inclusion to be successful. Otherwise, the word inclusion only means being physically present in general education schools". These statements underscore the fact that the speaker is not assuming any professional responsibility for implementing inclusion. Professional responsibility for changing the conditions is ascribed to other factors, like infrastructures and an achievement-oriented policy.

These findings demonstrated a division between declared attitudes towards inclusion, and the de-facto implementation of inclusion. It arises some doubt as to the DH willingness to struggle to implement inclusion in teacher education colleges.

\section{The Role of Teacher Education in Implementing Inclusion}

The second research question examined the role of teacher education for the implementation of inclusion and by thus creating a change in the implementation of inclusion. The discussion revolved around three topics: the content of training; when the necessary knowledge should be taught to teachers of inclusive classrooms; and the training programs that are currently available.

The content of the program. The DH discussed the content which they believed should be included in the curriculum for pre-service teachers. Two central topics were identified: knowledge and attitudes.

Nurturing knowledge and positive attitudes towards the inclusion of pupils with special needs was cited as important by primary education department heads: “...both knowledge during initial training and attitudes as well; perhaps beginning with attitudes and afterwards knowledge, or perhaps both in combination"; and was emphasized even more strongly by the heads of the special education departments: "I want to remind everyone that all the changes by different protest groups, were a result of positive attitudes". "The whole idea of inclusion grew out of positive attitudes, and once attitudes are positive, it's possible to implement everything".

Primary education DH maintain that knowledge of inclusion should be fostered. It seems that their own lack of knowledge is one of the reasons for their emphasis on inculcating knowledge, rather than on fostering positive attitudes among the pre-service teachers. At the discussion on this topic, the heads of the primary education departments mentioned their own personal lack of knowledge as a factor affecting their ability to assume professional responsibility for instilling the inclusive approach to education. Speakers noted openly about being unknowledgeable about inclusion: "It doesn't mean that I know a lot about inclusion"; "When I studied teaching and education, the Inclusion Law hadn't been legislated, and I didn't learn about that topic". 
The participants' expectation was that they would receive the knowledge they were lacking from special education professionals. Their reaction to the invitation by the researchers to discuss the topic reflects this: "I think we ought to hear from you about inclusion policy, you (the researchers who specialize in special education) should explain the policy, this is what I need to hear from you, I need to hear about the attitudes of policy-makers at the Ministry of Education. We can learn best from you". The way in which the discussion developed led us to the conclusion that their statements reflected an avoidance of their own responsibility to engage with this topic. In the course of the discussion, it became clear that the participants believe that it is the role and responsibility of special education educators to provide them with knowledge on the subject.

When should the knowledge be imparted. There was no consensus among the DH as to when pre-service teachers should acquire the necessary knowledge. The opinions varied in all of the forums. It seems that the lack of consensus is related to the degree of responsibility that the individual heads of departments assume for teaching pre-service teachers the necessary changes needed in the implementation of the inclusion policy. Accordingly, those DH who take responsibility contend that the subject should be taught at the first stage of training: “...to avoid creating a situation in which a student graduates from a teacher education college without having taken at least one introductory course on the philosophy of special education. Some knowledge about the law and about the relevant populations". Their sense of responsibility, we note, is reflected in their desire to inculcate knowledge about the rationale underlying inclusion, and the methods of teaching pupils with special needs.

Some also saw an advantage in imparting knowledge during the stage of actual teaching, as an aspect of professional specialization and development. “...the knowledge is the sort that develops, it's lifelong learning. It's not knowledge that they must acquire during initial training". That is, the assumption is that teachers continue to develop professionally throughout their careers and will encounter the knowledge needed to implement inclusion. These DH did not view teaching about the implementation of inclusion as part of their role, and transferred the responsibility to the professional development stage; in other words, as part of future teacher in-service education. They noted two advantages: one, the relevance and significance of that knowledge to needs which arise when actually teaching in an inclusive setting: "When they take the course during pre-service training, it's all well and good, but it goes in one ear and out the other because it's theoretical. And when they meet the children, it's very meaningful". Another advantage stems from the assumption that the initial training department requires a broad basis of knowledge beyond the issue of the inclusion of pupils with special needs. Deferring acquisition of that knowledge lightens the burden of content during initial training. "No, I don't really think that pre-service training is the key. I think that this training is for a very short period, with many options, and very preliminary. It's important and substantive, of course, but it's only the beginning".

The current programs. The heads of the early childhood and primary education departments presented various models for educating pre-service teachers for inclusive teaching. It is worth noting, that the models they described focused on a formal description of the number of courses offered with far less discussion of the contents. The different scope of the models available in the various colleges, can be explained in two ways - on the one hand, the needs that arise in the schools: "Our departments offer courses in special education because there are children with special needs in general classrooms", and on the other hand, the binding directives of the Council for Higher Education: "It's not so much a question of how I see it, there's the 'Ariav Framework', and there's a special education course of 10 weekly hours that required courses for primary-education pre-service 
teachers". It's seems that the general education DH see themselves as complying with the policy requirements stipulated by the Education Ministry and the "Ariav Framework". They refused to express their personal opinions and to take professional responsibility for adapting training content to the changing demands of inclusion: "We're here as heads of primary education departments, not in order to express our personal opinions"; "As the head of a department my personal opinion doesn't make any difference".

Particularly noteworthy among the heads of the special education departments were the participants who sought to contribute to training teachers in the general education departments, and who proposed that: "Shared courses and shared experiences (between students in the departments) are necessary. Everything will develop from that". It was also clear that those participants are motivated by their personal, positive attitudes towards the inclusion of pupils with special needs and they expand the boundaries of responsibility beyond their role-definition. We see that they position themselves as filling an academic managerial position by taking an active role in social terms, and they believe that promoting inclusion is vital. They take on a role that will lead to implementing inclusion according to their definition of the concept.

As we saw at the answering for the first question, we can see too, variation among the $\mathrm{DH}$ as to the role they take as having management positions. There are DH who take responsibility for implementation of the inclusion policy not only to fulfil the policy of teacher education. Not all of the DH act this way.

\section{Discussion}

The inclusion of pupils with special needs in general education is a social value. The education system is required to implement that as policy. Institutions of teacher education which form part of the education system are also required to implement that policy by training future teachers for teach in inclusive classes. The findings of this and other research studies (Avissar, Gilor, Licht, \& Shavit, 2013) show that not all teacher education institutions accept the professional responsibility for implementing inclusion. The differences are reflected in the varying number of courses that each college offers that covering the content required to implement inclusion. Programs with more courses means more knowledge to the pre service students. This move by the DH can indicate their willingness to promote the necessary change to implement a policy of inclusion of pupils with special needs.

The literature shows that the way in which teachers define their professional identity impacts on their attitudes toward educational changes and reforms (Beijaard, Verloop, \& Vermunt, 2000). Similarly, the professional identity of teacher educators influences their role in promoting educational reforms (Kalvir \& Kozminsky, 2010). In the present study, we found a shared belief among all DH that every learner has the right to be included in general education; we, however, did not discover a common sense of professional identity among them. That disparity resulted in differences between the various departments with relation to changes needed for implementing inclusion.

Our findings show that there are differences among the DH in terms of the knowledge they possess about the inclusion of pupils with special needs in general education. Some of them admitted that they had never studied the subject. The lack of knowledge can explain some of the differences in their professional identities and in their role-positioning. The DH with more knowledge included more courses dealing with the implementation of inclusion in their training models.

Position theory is based on the assumption that there are many roles in the social world and those involved in that world shape their identity in accordance with the roles available to them (Gee, 2000-2001). The 
availability of the role and positioning are open and flexible. The choice of how every group of DH perceives its role is connected to positioning within the role. Our study shows that DH have different perceptions of their roles for implementing the policy of inclusion. We found that they interpret policy according to how they position themselves in their role, and in accordance with their own knowledge of the subject. There are differences in the how DH position their roles as policy-makers for the department they are responsible for, and hence the differences in each one's sense of their own capability to decide on the number and content of the courses offered. Therefore, in some cases, the role perception of DH does not include implementing inclusion policy, and thus do not see themselves as leaders of the change needs to be done. The absence of this implementation finds expression in two aspects: professional responsibility, and setting the policy of their department. Do they see themselves as qualified to decide whether to admit students with special needs students into their own departments? This is a question of professional responsibility. Do they determine the models for training their students? This is a policy-making question.

For example, examining the directives of the new guidelines for teacher education framework reveals that it calls for addressing the "learning-teaching processes required for pupils with special needs and from different sociocultural backgrounds" (New Guidelines for Teacher Education, 2008, section 6, page 9). Like all the other directives in the framework, this one grants DH a degree of autonomy in choosing the courses' scope and contents. Despite the framework's flexibility, the participants cited it as a factor that impedes the design of the curriculum of the departments under their responsibility. "Look, above all there's the Ariav Framework. Let's assume that I object to inclusion, this is irrelevant-because I am bound by the Ariav Framework". Relating to the framework in this manner indicates an attitude that refuses to take professional or personal responsibility and places responsibility onto the limitations of an external document. Hence, the DH position themselves as carrying out policy, and less as setting policy.

\section{Recommendations}

The following recommendations stem from our conclusions. We recognize the need for a more thorough explanation and interpretation of inclusion policy in teacher education colleges. Explaining this policy should encourage the expansion of knowledge and the creation of more positive attitudes of pre-service teachers towards the inclusion of pupils with special needs. The knowledge they must acquire should include teaching strategies, characteristics of pupils with special needs, and a sound understanding of the principles of inclusive teaching. To influence teacher education, changes in two directions are needed: incorporating the concept of inclusion as part of the professional identity of the heads of departments, and emphasizing the professional development of teacher educators.

\section{Incorporating Inclusion Policy as Part of the Professional Identity of Department Heads}

DH have academic managerial positions and are therefore required to set policy for their units in accordance with economic, technological, political, and social changes (Kezar \& Eckel, 2002). Implementing this requirement must be part of their professional identity as well as a result of the directives they receive from those introducing the reforms. Inclusion is an educational reform that must become an integral aspect of the professional identity of teacher-training department heads. Kalvir and Kozminsky (2010) contend that to advance a reform or educational change, new perceptions of the role must be structured which include the proposed change, so that these become part of the fabric of educators' perceptions of their professional identity. 
Welmond has shown that in order to advance reforms, a connection must be created between the proposed changes and "the themes that already form part of the teacher's professional identity" (Welmond, 2002, p. 60). Teachers create a professional identity by means of their interactions with others. That identity influences the degree of their satisfaction with their roles and also determines to a great extent their attitudes toward changes and reforms in education. Empower dialogue can enable the creation of a "dynamic professional identity" which is alert to complexities, continues to grow, and promotes changes and reforms in education (Kalvir \& Kozminsky, 2010).

\section{Professional Development of Teacher Educators}

The lack of knowledge about inclusion found among DH highlights the need for the professional development of teacher educators. The need for professional development was also identified by the majority of the participants in our study. Professional development should include trends relating to inclusion throughout the world, successful models of inclusion, and the principles of teaching in inclusive classrooms.

Bearing in mind the important statements made during the discourse in the different forums, it would also be advantageous to hold discussions in the various interest groups. These discussions can be in the spirit of investigative dialogues mentioned previously. Establishing collaborative communities of practice can play a major role in developing the professional identity of teacher educators (Tuval, Barak, \& Gidron, 2011). We also recommend using case-studies from the literature and from the personal experience of the participants.

The recommendations above are due to present findings. Beyond them, we recommend to examine the perceptions of the $\mathrm{DH}$ at teacher education institutions anywhere in the world regarding the implementation of the inclusion policy and on any policy that requires change. Their support can be very helpful in implementing changes in the educational system.

\section{References}

Ainscow, M., Dyson, A., Goldrick, S., \& West, M. (2012). Making schools effective for all: Rethinking the task. School Leadership \& Management, 32(3), 197-213. doi:10.1080/13632434.2012.669648

Avissar, G., Gilor, O., Licht, P., \& Shavit, P. (2013). Perceptions of policy makers with regard to the inclusion of students with special educational needs (SEN)-Possible implications of these perceptions on teacher education. Research Report Submitted to MOFET Institute, Tel-Aviv, Mofet Institute. (In Hebrew).

Avissar, G., Reiter, S., \& Leyser, Y. (2003). Principals' views and practices regarding inclusion: The case of Israeli elementary school principals. European Journal of Special Needs Education, 18(3), 355-369.

Balas, N., \& Adler, C. (2004). Politics, education, and scientific knowledge: Are they interrelated? Megamot: Reserch, Policy and Politics In Education, 43(1), 10-32. (In Hebrew)

Beijaard, D., Verloop, N., \& Vermunt, J. D. (2000). Teachers' perceptions of professional identity: An exploratory study from a personal knowledge perspective. Teaching and Teacher Education, 16(7), 749-764. Retrieved from http://search.proquest.com/docview/62345057? accountid=41221

Day, C., Sammons, P., Hopkins, D., Harris, A., Leithwood, K., Gu, Q., Brown, E., Ahtaridou, E., \& Kington, A. (2009). The impact of school leadership on pupil outcomes (Final Report). DCSF Research Report RR108, University of Nottingham.

Director-General's Bulletin, 2008/3 (D) 1 November 2007. (In Hebrew). Retrieved from http://cms.education.gov.il/education cms/applications/mankal/etsmedorim/1/1-2/horaotkeva/k-2008-3d-1-2-37.htm

Donnelly, V. (2010). Teacher education for inclusion: International literature review. European Agency for Development in Special Needs Education. Odense, Denmark: European Agency for Development in Special Needs Education.

Dorczak, R. (2011). School organisational culture and inclusive educational leadership. Contemporary Management Quarterly/Wspólczesne Zarzadzanie, 2, 45-55.

Fishbein, M., \& Ajzen, I. (2010). Predicting and changing behavior: The reasoned action approach. New York: Psychology Press (Taylor \& Francis). 
Forlin, C. (2010). Re-framing teacher education for inclusion. In C. Forlin (Ed.), Teacher education for inclusion: Changing paradigms and innovative approaches (pp. 3-10). Abingdon: Routledge.

Graham, L. J., \& Spandagou, I. (2011). From vision to reality: Views of primary school principals on inclusive education in New South Wales, Australia. Disability \& Society, 26(2), 223-237. doi:10.1080/09687599.2011.544062

Kalvir, R., \& Kozminsky, L. (2010). The construction of professional identity: Processes of teacher education and professional development. Tel-Aviv, Mofet Institute. (In Hebrew)

Kedem, Y., Fakhereldeen, M., \& Ben-Israel, T. (2012). A Framework for the training and development of academic managers in higher education. Journal of International Scientific Publications: Educational Alternatives, 10, 116-124.

Kezar, A. J., \& Eckel, P. D. (2002). The effect of institutional culture on change strategies in higher education. The Journal of Higher Education, 73, 435-461.

Marshall, S. J., Adams, M. J., Cameron, A., \& Sullivan, G. (2000). “Academics” perception of their professional development needs related to leadership and management: What can we learn? International Journal for Academic Development, 5(1), 42-53.

Muijs, D., Ainscow, M., Dyson, A., Raffo, C., Goldrick, S., Kerr, K., ... Miles, S. (2010). Leading under pressure: Leadership for social inclusion. School Leadership \& Management, 30(2), 143-157. doi:10.1080/13632431003663198

New guidelines for teacher education. Decision no. 1084/10 of the Council for Higher Education as amended on January 29th, 2008 and July 1st, 2008. (In Hebrew). Retrieved from http://cms.education.gov.il/NR/rdonlyres/0D75DE48-FC6C-4723-B85 3-80866FDD0C0C/89475/__211106__ 1708.pdf

Sebba, J., \& Ainscow, M. (1996). International developments in inclusive schooling: Mapping the issues. Cambridge Journal of Education, 26(1), 5-18.

Sharma, U., Moore, D., \& Sonawane, S. (2009). Attitudes and concerns of pre-service teachers regarding inclusion of students with disabilities into general schools in Pune, India. Asia-Pacific Journal of Teacher Education, 37(3), 319-331. doi:10.1080/13598660903050328

Tervo, R. C., Palmer, G., \& Redinius, P. (2004). Health professional student attitudes towards people with disability. Clinical Rehabilitation, 18(8), 908-915. doi:10.1191/0269215504cr820oa

Titscher, S., Meyer, M., Wodak, R., \& Vetter, E. (2000). Methods of text and discourse analysis. London: Sage.

Tuval, S., Barak, J., \& Gidron, A. (2011). Negotiating a team identity through collaborative self-study. Studying Teacher Education, 7, 201-210.

Welmond, M. (2002). Globalization viewed from the periphery: The dynamics of teacher identity in the republic of benin. Comparative Education Review, 46(1), 37-65. 